\title{
As mulheres artistas da geração 80 em Curitiba e as estratégias de permanência na posição de vanguarda no início dos anos 2000
}

\author{
Artist women of generation 80 in Curitiba and \\ strategies of permanence in the vanguard position in
} the early 2000s

ADRIANA VAZ \& ROSSATO SILVA

ROSSANO SILVA

\section{Resumo}

0 artigo trata da circulação e representatividade de artistas mulheres no sistema de artes em Curitiba/PR, circunscrevendo o período entre 1980 a 2003. Cujo objetivo é identificar as estratégias de permanência no campo da arte de um grupo de mulheres que ingressam no mercado simbólico na década de 1980, nominada geração 80, e conservam posições de vanguarda no início dos anos 2000. Adota-se como principal aporte teórico Pierre Bourdieu, Néstor García Canclini e Sérgio Miceli, e autores que tratam da história da arte no Paraná: Ennio M. Ferreira, Ivens Fontoura, Maria J. Justino, Autor 1 e Arthur Freitas. Utiliza-se como fonte as publicações sobre a produção artística em Curitiba e analisa-se as premiações do Salão Paranaense, entre 1980 e 1989, mensurando a representatividade das

\footnotetext{
a Universidade Federal do Paraná, Curitiba, PR, Brasil. Doutora em Sociologia. E-mail: vazufpr@gmail.com

b Universidade Federal do Paraná, Curitiba, PR, Brasil. Doutor em Educação. E-mail: rossano.silva@ufpr.br 48

Rev. Caminhos da Educação: diálogos, culturas e diversidades, Teresina, v. 2, n. 3, p. 48-71, set./dez. 2020
} 
As mulheres artistas da geração 80 em Curitiba e as estratégias de permanência na posição de vanguarda no início dos anos 2000

mulheres artistas nesse período. Em síntese a representação das mulheres no Salão Paranaense ampliou a partir de 1980, se comparada as premiações distribuídas por gênero em edições anteriores. Nota-se que a permanência das mulheres na posição de vanguarda resultou dos vínculos sociais, educacionais e culturais que coloca o campo artístico em funcionamento, e as situa como intermediárias culturais ao atuarem como professoras, gestoras ou curadoras.

Palavras-chave: Arte paranaense, Artistas mulheres, Cultura, Gênero.

\section{Abstract}

This article presents the female artists circulation and representativeness in the arts system of Curitiba/PR, circumscribing the period between 1980 and 2003. Its objective is to identify the permanence strategies in the art field of a group of women who enter the symbolic market in the 1980s, which is known as the 80 s generation, and that maintain avant-garde positions in the early 2000s. Pierre Bourdieu, Néstor García Canclini and Sérgio Miceli, and also authors who depict the art history in Paraná such as Ennio M. Ferreira, Ivens Fontoura, Maria J. Justino, Autor 1 and Arthur Freitas are adopted as the main theoretical apport. The publications of artistic production in Curitiba are used as a source and the awards of Salão Paranaense, between 1980 and 1989, are analysed, measuring the representativeness of female artists in that period. In summary, the representation of women in Salão Paranaense has expanded since 1980, if compared to the awards distributed by gender in previous editions. It is observed that the permanence of women in the avant-garde position resulted from the social, educational and cultural ties that put the artistic field into operation, and situate them as cultural intermediaries when they act as teachers, managers or curators.

Keywords: Art from Paraná, Female Artists, Culture, Gender. 


\section{Resumen}

El artículo aborda la circulación y representatividad de las artistas femeninas en el sistema artístico en Curitiba / PR, circunscribiendo el período entre 1980 y 2003 . El objetivo de las mismas es identificar las estrategias de permanencia en el campo del arte de un grupo de mujeres que ingresan al mercado simbólico en 1980, conocida como la generación de los 80 , y mantienen posiciones de vanguardia a principios de la década de 2000. Pierre Bourdieu, Néstor García Canclini y Sérgio Miceli, y los autores que se ocupan de la historia del arte en Paraná, son adoptados como autores principales: Ennio M. Ferreira, Ivens Fontoura, Maria J. Justino, Autor 1 y Arthur Freitas. Las publicaciones sobre producción artística en Curitiba son utilizan como fuente y se analizan los premios en el Salón Paranaense, entre 1980 y 1989, que miden la representación de mujeres artistas en ese período. En resumen, la representación de las mujeres en Salón Paranaense se ha expandido desde 1980, al comparar los premios distribuidos por género en ediciones anteriores. Cabe señalar que la permanencia de las mujeres en la posición de vanguardia es el resultado de los lazos sociales, educativos y culturales que ponen en funcionamiento el campo artístico, y las sitúa como intermediarias culturales cuando actúan como maestras, administradoras o curadoras.

Palabras clave: Arte de Paraná, Mujeres artistas, Cultura, Género.

\section{Introdução}

Este estudo é um desdobramento da pesquisa sobre o sistema de artes em Curitiba tendo como foco o estudo das galerias de artes, em que se objetivava mapear os artistas atuantes em Curitiba e com obras expostas nas galerias, tendo como recorte temporal o período de 2000 a 2003. Para tanto foi feito um corte na trajetória artística do grupo, identificando seus vínculos com diferentes espaços de consagração. Dos espaços de consagração simbólica avaliou-se a participação no Salão Paranaense e em três mostras de vanguarda: Faxinal das Artes, realizada em 2002; Síntese do Paraná - Arte Atual, realizada em 2002; e do Acervo de Artes Plásticas da Fundação Cultural de Curitiba 
As mulheres artistas da geração 80 em Curitiba e as estratégias de permanência na posição de vanguarda no início dos anos 2000

(FCC), realizada em 2000. Por outro lado, como consagração comercial adotou-se como fonte a participação dos artistas no catálogo editado por Julio Louzada Publicações. Esses dois eixos de análise somaram-se ao pertencimento dos artistas nas 13 galerias de artes que compunham o estudo, seguindo a tipologia: comercial, intermediária e simbólica (AUTOR 1, 2004; 2019).

A partir da constatação que dos 42 artistas do grupo intermediário, a maioria eram homens e que a inserção das mulheres no mercado simbólico via Salão Paranaense amplia-se a partir de meados da década de 1970, indaga-se: Quais papéis as mulheres artistas da Geração $80^{\mathrm{i}}$ desempenharam em suas trajetórias profissionais que as coloca em posição de vanguarda no início dos anos 2000? Com o intuito de verificar a representatividade de artistas mulheres no campo das artes em Curitiba, adota-se como fonte duas publicações sobre o Salão Paranaense: 1) Paranaenses mais premiados nas 42 edições do Salão Paranaense; 2) 50 anos do Salão Paranaense de Belas Artes.

$\mathrm{O}$ artigo divide-se em quatro tópicos: os dois primeiros, apresenta-se os dados que seguem o estudo das galerias de arte (AUTOR 1, 2004); e os dois últimos avalia-se as premiações e os vínculos das mulheres com o Salão Paranaense, conduzindo o olhar para o interstício de 1980 a 1989.

\section{Artistas mulheres e o trânsito entre as Galerias intermediárias e o Salão Paranaense}

No campo da arte para o artista manter-se na posição de vanguarda exige-se que a obra produzida tenha valor por si mesma, o artista descola-se das exigências materiais que implica o próprio viver. Esse modelo de comportamento é transmitido nos diversos canais de legitimação da arte, isto é, o habitus artístico é instituído e mantido pelo ensino superior e demais instâncias simbólicas como as exposições artísticas, as publicações em catálogos etc. Para tanto o mercado de bens simbólicos é gerenciado por diversos agentes - os críticos de arte, os professores de arte, os jornalistas, os curadores, os galeristas, os marchands -, profissionais responsáveis pela manutenção da oferta aos novos produtores como alude Pierre Bourdieu (2002, p. 21-26).

Rev. Caminhos da Educação: diálogos, culturas e diversidades, Teresina, v. 2, n. 3, p. 48-71, set./dez. 2020 
Nesse sentido, para o campo da arte, os intermediários culturais desempenham a função de conservar as posições já ocupadas e regular a entrada de novos agentes no campo erudito. Muitos artistas atuam em outras áreas dentro do sistema de arte desempenhando a função de intermediários culturais, Néstor García Canclini (1986, p. 64) os define como "distribuidores da arte". A obra de arte, para Canclini (1986), deve ser entendida como produção e não como pura significação, porque consiste numa apropriação e numa transformação da realidade material e cultural, mediante um trabalho, para satisfazer uma necessidade social, de acordo com a ordem vigente em cada sociedade.

A polarização entre arte como pura significação (erudita) e a arte como mercadoria (comercial) estrutura o campo artístico para Bourdieu (2001, p.105). Pela qual na lógica do campo as galerias de arte reproduzem em sincronia a história dos movimentos artísticos desde a ruptura realizada por Manet, pois cada uma das galerias foi uma galeria de vanguarda e é tanto mais consagrada quanto mais as obras as consagram. Isto é, cada galeria tem sua marca própria e é reconhecida por esta marca recebe classificações distintas podendo ser considerada uma galeria de vanguarda ou comercial - diferença que representa a estrutura natural de classificação dos bens simbólicos (BOURDIEU, 1996, p.182).

Através dessa lógica estrutural, o campo artístico e a consagração da obra de arte giram em torno do capital simbólico do artista, a construção desse valor que é reconhecido entre os pares compete ao intelectual como alude Carlos E. Vieira (2006). O autor apresenta três teorias distintas para tratar do papel político dos intelectuais a de: Karl Mannheim, Antonio Gramsci e Pierre Bourdieu. Em acordo com Vieira (2006, p. 9),

\begin{abstract}
P. Bourdieu enfatizou os mecanismos de reprodução social, a partir de uma análise das relações (homologia) entre dominação econômica e dominação cultural; entre estruturas mentais e simbólicas e estruturas sociais. Segundo Bourdieu o poder simbólico produz uma eufemização do poder material; transforma o capital econômico em capital cultural, de tal maneira que posições assumidas em nome da técnica, da ciência ou das leis sejam determinadas pelos interesses de classe.
\end{abstract}

Em função dessa transformação do capital econômico em capital simbólico, no estudo das galerias de arte em Curitiba mapeou-se três tipos: as de vanguarda, as intermediárias e as comerciais. As galerias intermediárias situam-se ao meio caminho dos dois polos, compunham o grupo seis espaços: Fraletti Rubbo, Acaiaca, Noris Espaço de Arte, Galeria Simões de Assis, Solar do Rosário e Manolo Saez. Numericamente as

Rev. Caminhos da Educação: diálogos, culturas e diversidades, Teresina, v. 2, n. 3, p. 48-71, set./dez. 2020 
As mulheres artistas da geração 80 em Curitiba e as estratégias de permanência na posição de vanguarda no início dos anos 2000

galerias intermediárias tinham 197 obras, incluindo a produção de 37 homens e 15 mulheres, dos quais: 10 homens e 12 mulheres tinham vínculo apenas com as galerias intermediárias, e 17 homens e 3 mulheres expuseram suas obras nas galerias intermediárias e comerciais como alude Autor 1 (2004).

O quadro 1 destaca as artistas mulheres com obras nas galerias intermediárias e comerciais, indicando também a participação e premiação no Salão Paranaense entre 1944 a 2003, ou seja, situa-se nesse primeiro momento as mulheres atuantes no mercado de artes visuais no início dos anos 2000, residentes em Curitiba.

Quadro 1: ARTISTAS MULHERES: PARTICIPAÇÃO NAS GALERIAS DE ARTE (2000-2003) E NO SALÃO PARANAENSE (1944-2003) *

\begin{tabular}{|c|}
\hline GALERIAS INTERMEDIÁRIAS E PARTICIPAÇÕES NO SALÃO \\
PARANAENSE \\
\hline $\begin{array}{c}\text { 07 com participação: Mazé Mendes (1976/1987), Jussara Age (1977/1983), Denise } \\
\text { Roman (1980/2000), Uiara Bartira (1981/1983), Guita Soifer (1981/1986), Juliane } \\
\text { Fuganti (1984/2001), Dulce Osinski (1984/2002) }\end{array}$ \\
05 sem participação: Claudia Capelli, Daniele Henning, Dalwa Lobo, Lizeti Zen, \\
Simone Tanaka \\
\hline GALERIAS INTERMEDIÁRIAS/COMERCIAIS E PARTICIPAÇÕES NO \\
SALÃO PARANAENSE \\
\hline 01 com participação: Corina Ferraz (1990) \\
\hline 02 sem participação: Miriam Martins, Vivian Vidal
\end{tabular}

* Foram considerados as artistas mulheres pertencentes ao recorte da pesquisa nas galerias de arte. Em negrito as artistas com participação nas exposições de vanguarda.

Fonte: Autor 1 (2004).

O vínculo das artistas mulheres no Salão Paranaense ocorreu a partir de meados da década de 1970 (quadro 1) indicado pela primeira e última participação, dentre elas: Mazé Mendes expõem entre 1976 e 1987, no total de seis participações e duas premiações; Denise Roman participa entre 1980 e 2000, no total de oito mostras e recebe duas premiações; Uiara Bartira teve duas participações: 1981 e 1983, e uma premiação;

Rev. Caminhos da Educação: diálogos, culturas e diversidades, Teresina, v. 2, n. 3, p. 48-71, set./dez. 2020 
Guita Soifer participou entre 1981 e 1986, totalizando três mostras e uma premiação; Juliane Fuganti estende sua participação entre 1984 e 2001, em 8 salões e teve uma premiação; Dulce Osinski também teve 8 participações, a primeira 1984 e a última em 2002, obtendo uma premiação; Jussara Age com duas participações: 1977 e 1983, e uma premiação; por fim, Corina Ferraz com uma participação em 1990. (Autor 1, 2004, p.8788). Dentre essas 15 mulheres, apenas 4 artistas participaram das exposições de vanguardas realizadas entre 2000 e 2003, no caso as mostras: Acervo da FCC, Síntese do Paraná, e Faxinal das Artes. O que sinaliza que o campo da arte renova uma parcela de seus membros a cada geração nos termos de Bourdieu (1996).

Os tópicos a seguir elucidam sobre a participação das mulheres nas exposições de vanguarda e, depois, adota-se as publicações sobre a arte paranaense em circulação na década de 1980, em especial as do Salão Paranaense.

\section{Artistas mulheres na posição de vanguarda: idade biológica e idade artística}

A exposição promovida pela Fundação Cultural de Curitiba (FCC), em 2000, adquiriu para o seu acervo de artes plásticas 94 obras de 12 artistas paranaenses, que passaram a pertencer à Coleção Contemporânea Curitiba 2000, acervo permanente do Museu Metropolitano de Arte de Curitiba e do Museu da Gravura Cidade de Curitiba. As obras foram adquiridas pela Siemens através da Lei Municipal de Incentivo à Cultura. Os curadores foram: Alberto Puppi, Adriana Berbeka, Paulo Reis e Simone Landal. Dentre os artistas, oito homens selecionados totalizando 75 obras, e quatro mulheres perfazendo 19 obras, a saber: Dulce Osinski (6 obras), Eliane Prolik (5 obras), Laura Miranda (5 obras) e Carina Weidle (3 obras).

A segunda mostra é a Síntese do Paraná: Arte Atual realizada em 2002 na Casa Andrade Muricy tendo como organizador o diretor Ennio M. Ferreira. A seleção dos artistas, limitada a dez participantes, foi feita pela comissão julgadora composta também por dez profissionais da área de artes visuais, que atuaram como curadores individuais dos artistas. Dos quais tem-se as duplas, artistas e curadores, respectivamente: Carina Weidle com Eliane Prolik, Dulce Osinski com Tânia Bloomfield, Edilson Viriato com Fernando Bini, Elvo Benito Damo com Maria José Justino, Fábio Noronha com Ronald Simon, José Antonio de Lima com Maria Cecília Araújo de Noronha, Juliane Fuganti com Sergio Kirdziej, Luiz Carlos Brugnera com João Henrique do Amaral, Maria Cheung com Adalice Maria de Araújo, Marlon de Azambuja com Nilza Knechtel Procopiak. 
As mulheres artistas da geração 80 em Curitiba e as estratégias de permanência na posição de vanguarda no início dos anos 2000

Nessa mostra a participação entre homens e mulheres mantem-se equilibrada, sendo quatro mulheres na posição de artistas: Carina Weidle, Dulce Osinski, Juliane Fuganti, Maria Cheung. E seis mulheres na posição de curadoras: Eliane Prolik, Tânia Bloomfield, Maria José Justino, Maria C. Araújo de Noronha, Adalice Araújo e Nilza Knechtel.

O Faxinal das Artes, terceira mostra que compunha o estudo das galerias de arte, era um evento que conjugava um programa de residência artística com a constituição de um acervo de arte contemporânea. O programa selecionou aproximadamente cem artistas de todo o Brasil. O Faxinal das Artes foi realizado pela Secretaria de Estado da Cultura do Paraná, no período de 17 a 31 de maio de 2002, em Faxinal do Céu. Dentre os cem artistas do Brasil, trinta eram do Paraná, incluindo as cidades de Curitiba, Londrina, Cascavel e Foz do Iguaçu; sendo que, o número de artistas vinculados às galerias de arte era pequeno: Débora Santiago, Dulce Osinski, Glauco Menta, Guita Soifer, José Antonio de Lima, Marlon de Azambuja e Mazé Mendes. Desses 30 artistas tem-se a participação de 18 mulheres atuantes no Paraná: Alice Yamamura, Ana Gonzáles, Bernadete Amorim, Conceição Rodriguez, Débora Santiago, Deise Marin, Didonet Thomaz, Dulce Osinski, Gleyce Cruz, Guita Soifer, Laura Miranda, Letícia Faria, Mainês Olivetti, Marga Puntel, Maria Cheung, Mazé Mendes, Rossana Guimarães, Tânia Bloomfield.

Considerando as três mostras, a maioria das mulheres nasceram entre 1950 e 1969, em hipótese, representaria o reconhecimento simbólico entre 1970 e 1989, respectivamente. De um lado, apresenta-se as 11 mulheres nascidas entre 1950 e 1959: Alice Yamamura (1954), Ana Gonzáles (1951), Bernadete Amorim (1955), Conceição Rodriguez (1959), Didonet Thomaz (1950), Laura Miranda (1958), Letícia Faria (1953), Mainês Olivetti (1952), Maria Cheung (1957), Mazé Mendes (1950), Rossana Guimarães (1958). De outro, lista-se as 7 mulheres que nasceram entre 1960 a 1969: Carina Weidle (1966), Deise Marin (1965), Dulce Osinski (1962), Eliane Prolik (1960), Gleyce Cruz (1969), Marga Puntel (1964), Tânia Bloomfield (1963). Sendo que, Guita Soifer nasceu em 1935 e Débora Santiago em 1972. (Autor 1, 2004, p.207-208).

Rev. Caminhos da Educação: diálogos, culturas e diversidades, Teresina, v. 2, n. 3, p. 48-71, set./dez. 2020 
Do grupo de artistas, Soifer faz sua primeira participação no Salão Paranaense, em 1981, e Osinski, em 1984, o que elucida a priori que as artistas que nasceram na década de 1930 tiveram um reconhecimento tardio em Curitiba considerando a trajetória de Soifer em comparação a Osinski, artista da “geração 80". A geração ou década da qual o artista pertence ou representa na história da arte é denominado em função do período em que o artista é aceito pelos vários canais de legitimação e veiculação da produção artística, ou seja, a data que o artista participa dos primeiros salões de arte ou que realiza suas primeiras exposições individuais. Mesmo que muitos artistas continuem participando de mostras nas décadas posteriores - a exemplo do Salão Paranaense - o artista é identificado pela década do seu ingresso no sistema oficial da arte.

Para Bourdieu (1996, p.170-179) o alinhamento entre essas duas idades faz parte das regras do campo artístico. Fica claro que o valor que o campo de produção cultural confere à juventude remete, mais uma vez, à denegação do poder e da economia que está em seu fundamento, ou por atributos de vestuário, ou pela hexis corporal. Portanto, o fator idade é uma característica que define posições e se torna uma variável constante dentro do campo - a média constatada na pesquisa das galerias de arte varia entre 17 a 25 anos como alude Autor 1 (2004). Considerando esses dois critérios, a data de nascimento e a data dos primeiros vínculos oficiais, indaga-se: Quem são as artistas mulheres com representatividade simbólica na década de 1980 no Paraná?

\section{A representatividade das artistas mulheres nas 42 edições do Salão Paranaense}

Ferreira (1986) ao tratar do Paraná contemporâneo elenca vários fatores que corroboram para que as estruturas de formação e aperfeiçoamento do artista se consolidem e possibilitem a constituição de um sistema de artes em Curitiba, a partir da década de 1970: a criação da Fundação Cultural de Curitiba (FCC), em 1973, e da Secretaria da Cultura e do Esporte, em 1979. Dentre os museus destaca a instalação e implantação de um corpo funcional do Museu de Arte Contemporânea do Paraná (MAC/PR), do Museu Alfredo Andersen e do Centro Juvenil de Artes Plásticas (CJAP). E quanto as estruturas de ensino superior menciona a Escola de Música e Belas Artes do Paraná e a Faculdade de Educação Musical do Paraná.

Específico ao MAC/PR, Ellen Biora (2019) destaca a importância dessa instituição, um museu vivo, como catalisador da arte contemporânea e seu vínculo com as atividades educativas no interstício entre 1970 a 1984, pela qual destacamos os gestores

Rev. Caminhos da Educação: diálogos, culturas e diversidades, Teresina, v. 2, n. 3, p. 48-71, set./dez. 2020 
As mulheres artistas da geração 80 em Curitiba e as estratégias de permanência na posição de vanguarda no início dos anos 2000

nas décadas de 1970 e 1980: Fernando Velloso (1970-1983), Mariza Bertoli (1983-1984), Elizabeth Titton (1984-1987), Adalice Araújo (1987-1988). Sobre a Faculdade de Educação Musical do Paraná (FEMP/FAP) Jacyara B. Santini (2015) elucida os vínculos com a Casa Alfredo Andersen essenciais para viabilizar o funcionamento de um curso de licenciatura plena em Educação Artística, com habilitação em Artes plásticas, em 1974.

Deslocando a atenção para os artistas e não para as estruturas que compõem o campo artístico em Curitiba, e no Paraná, Ferreira (1986) menciona a contribuição artística de Bia Wouk, Carlos E. Zimmermann, Rones Dunke e Ruben Esmanhoto, ligado ao design menciona o trabalho de Marcos Bento. Com propensão em atuar no circuito nacional destaca a produção de Alfi Vivern, Claudio Alvarez, Elvo Benito Damo, Estela Sandrini, Francisco Faria, Letícia Faria, Luiz Henrique Schwanke, Uiara Bartira. Ainda como parte do panorama artístico paranaense destaca a produção de escultura popular, pintura primitiva e tapeçaria; assim como os artistas ligados a "arte não convencional" como Heloísa Campos, Ivens Fontoura, João Osório, Jorge Carlos Sade, Lauro Andrade, Luiz Rettamozo, Márcia Simões, Margareth Born, Marcos Bento e Olney Negrão. Entre outros com propostas recentes: Lizete Chipanski, Sérgio Moura, Sonia Gutierrez e Vilmar Nascimento. Dos 27 artistas, e desenhistas, elencados por Ferreira tem-se 18 homens e nove mulheres.

Dentre as obras datadas que compõem o catálogo "Tradição e Contradição" realizada no MAC/PR, em 1986, complementa-se com outros 13 artistas, oito homens e cinco mulheres, considerando a fase de produção entre 1975 a 1986: Annette Skarbek, Antonio Alves Ferreira, Aristide Brodeschi, Carmen Carini, Janete Fernandes, João Pilarski, Jussara Age, Laura Miranda, Lafaete Rocha, Luiz Antonio Guinski, Paulo Menten, Raul Cruz e Rogério Dias. Período que Ferreira (1986) nomina como “contemporâneo".

Nessa mesma publicação, Fontoura (1986) ao falar sobre a "explosão criativa" da década de 1970 no Paraná destaca as ações institucionais já enunciadas por Ferreira (1986) e faz menção aos cursos de arte e design da Universidade Federal do Paraná, ao

Rev. Caminhos da Educação: diálogos, culturas e diversidades, Teresina, v. 2, n. 3, p. 48-71, set./dez. 2020 
ateliê do CAPE ${ }^{\mathrm{ii}}$, ao Projeto Universidade - UNIARTE, e salienta a produção de alguns artistas do período. Referente a produção artística, Fontoura (1986) elenca: Cerzo, Fernando Bini, Francisco Kava Sobrinho, Ivens Fontoura, Lauro Andrade, Olney da Silva Negrão, Rettamozo, Sérgio Moura e Walter Montenegro; e entre as mulheres tem-se: Ana Gonzáles, Eliane Borges de Almeida, Márcia Simões, Margareth Born e Margarida Weisheimer. Também como polo catalisador de uma arte não convencional, Fontoura (1986) menciona a sua participação na organização dos Encontros de Arte Moderna juntamente com Adalice Araújo, os quais tiveram a duração aproximada de uma década e seu primeiro encontro ocorreu em 1969, com acento para o evento de 1974. Destaca a colaboração de Fernando Bini, formando da EMBAP, e Lauro Andrade, presidente do Diretório Acadêmico Guido Viaro da EMBAP.

Dos egressos do ano de 1969 e 1970 que conviveram com os Encontros e posteriormente atuaram no ensino superior em Curitiba, tem-se: Toshiyuki Sawada, Márcia Simões, Fernando Bini e Maria Cecília Araújo Noronha. Seguido das gerações posteriores como os docentes Maria José Justino, Sérgio Kirdzej, João Berberi (Beda); e de artistas como Carmen Carini, Elvo Benito Damo, Jarbas Schunemann, Marbareth Born, Nilza Knechtel, Pedro Maes, Sonia Gutierrez e Tokio Sato. ${ }^{\text {iii }}$

Reforçando o aspecto vanguardista dos Encontros de Arte Moderna Arthur Freitas (2013) destaca a participação de artistas e críticos de outros estados brasileiros.

Centrados na discussão estético-ideológica sobre os limites das linguagens de vanguarda, os eventos tenderam a potencializar a associação entre arte experimental, liberdade comportamental e contracultura, num contexto em que estiveram presentes em Curitiba artistas como Artur Barrio, Ana Bella Geiger, Pietrina Checcacci, Frederico Nasser, José Rezende, Pedro Escosteguy e Josely Carvalho, além de críticos como Frederico Morais, Roberto Pontual, Mário Barata e Walmir Ayala (FREITAS, 2013, p.1).

Do contexto local, Freitas faz menção a Adalice Araújo, Lauro Andrade, Márcia Simões, Fernando Bini, Ivens Fontoura, Paulo Leminski, Oraci Gemba e Sylvio Back, cada qual com suas especificidades artísticas e estéticas participaram ativamente dos eventos, e faz menção a três ações de cunho estético, político e comportamental. O "Sábado de criação" realizada em 1971 foi proposta por Frederico Morais, validada por Adalice Araújo e fotografada pelo arquiteto Key Imaguire Júnior. A segunda em 1972 foi 
As mulheres artistas da geração 80 em Curitiba e as estratégias de permanência na posição de vanguarda no início dos anos 2000

batizada de "Arte total", uma intervenção também mediada por Frederico Morais que convida João Moderno, Artur Barrio e Valkyria Proença para realizarem sua interferência no espaço do MAC/PR, Fernando Velloso era o diretor do museu nessa ocasião. E em 1974 a ação “Gincana Ambiental” proposta pela artista Josely de Carvalho, a qual já havia realizado uma proposta semelhante no México (FREITAS, 2013). Nas palavras de Freitas (2013, p. 13): “as ações parecem dispostas a problematizar a segurança simbólica e material do circuito de arte, com seus sentidos e valores específicos", ou seja, os encontros rompiam com o modelo de proposta artística atrelada "a belas artes" ainda presente no imaginário do público curitibano.

Além dos Encontros de Arte Moderna, outro ponto de destaque apresentado por Fontoura (1986) como um desdobramento dessa ruptura artística local, uma continuação das ações da década de 1970, foi a atuação de grupos de artistas como Caixa de Bixo, Convergência e Moto-Contínuo, assim como o movimento "Sensibilizar" e o projeto "Pró-Cocó". Uma parcela desses artistas enunciados por Ferreira (1986) e Fontoura (1986) tem suas produções vinculadas durante a década de 1970 e início dos anos 1980 via Salão Paranaense.

Ao analisar a publicação "Paranaenses mais premiados nas 42 edições do Salão Paranaense", publicado em 1986, pela Secretaria de Estado da Cultura e do Esporte juntamente com o MAC/PR, nota-se a participação das mulheres em cargos administrativos: Suzana Maria Munhoz da Rocha Guimarães estava à frente da Secretaria, Elizabeth Bastos Dias Titton no MAC/PR, e o texto de abertura dessa publicação foi escrito por Maria Cecilia Araujo Noronha. Sobre a representação das mulheres nessas edições, o quadro 2 lista as artistas com três ou mais premiações no Salão Paranaense considerando o período de 1944 a 1986, no total de 47 artistas.

Quadro 2: ARTISTAS MAIS PREMIADOS NO SALÃO PARANAENSE (1944-1986)

\begin{tabular}{|c|c|c|}
\hline $\begin{array}{c}\text { Década de } \\
\text { nascimento }\end{array}$ & Artistas homens & Artistas mulheres \\
\hline
\end{tabular}

Rev. Caminhos da Educação: diálogos, culturas e diversidades, Teresina, v. 2, n. 3, p. 48-71, set./dez. 2020 


\begin{tabular}{|c|c|c|}
\hline $\begin{array}{l}\text { Anterior a } \\
1890\end{array}$ & Franz Hohenlohe $(7 / 5)^{*}$ & \\
\hline 1891 a 1900 & $\begin{array}{l}\text { Estanislau Traple (12/4), Guido } \\
\text { Viaro (17/8), Paul Garfunkel (13/7), } \\
\text { Waldemar Curt Freyesleben (14/3) }\end{array}$ & \\
\hline 1901 a 1910 & $\begin{array}{l}\text { Arthur Nísio (9/6), Kurt Boiger } \\
\text { (9/4), Miguel Bakun (18/9), Oswald } \\
\text { Lopes (11/4), Theodoro de Bona } \\
(10 / 3) \text {, Werner Jehring }(12 / 6)\end{array}$ & \\
\hline 1911 a 1920 & $\begin{array}{l}\text { Nilo Previdi (18/9), Waldemar Roza } \\
(5 / 5)\end{array}$ & $\begin{array}{l}\text { Leonor Botteri }(10 / 8) \text {, } \\
\text { Sofia Dyminski }(8 / 3)\end{array}$ \\
\hline 1921 a 1930 & $\begin{array}{l}\text { Antonio Arney (17/8), Alvaro } \\
\text { Borges (8/4), Domicio Pedroso } \\
(9 / 6), \text { Fernando Velloso (12/8), João } \\
\text { Frederico Genehr (4/3), Jorge } \\
\text { Carlos Sade }(9 / 5), \text { Loio Pérsio }(7 / 4), \\
\text { Paulo Gnecco (4/4) }\end{array}$ & $\begin{array}{l}\text { Ida Hannemann de } \\
\text { Campos }(18 / 6)\end{array}$ \\
\hline 1931 a 1940 & $\begin{array}{l}\text { Alcy Xavier }(9 / 3), \text { Fernando } \\
\text { Calderari }(10 / 7), \text { Francisco Kava } \\
\text { Sobrinho }(9 / 5), \text { Ivens Fontoura } \\
(5 / 3) \text {, Jefferson Cesar }(13 / 6), \\
\text { Lafaete Rocha }(5 / 3), \text { Luiz Carlos } \\
\text { Andrade Lima (10/5), Mário } \\
\text { Rubinski (27/8), Vicente Jair } \\
\text { Mendes }(11 / 4)\end{array}$ & $\begin{array}{l}\text { Helena Wong (14/9), } \\
\text { Isabel Bakker (6/4) }\end{array}$ \\
\hline 1941 a 1950 & $\begin{array}{l}\text { Elvo Benito Damo (6/4), João } \\
\text { Osório Brzezinski (11/10), Luiz } \\
\text { Carlos Rettamozzo (4/4), Osmar } \\
\text { Chromiec (12/6), Rogério Dias } \\
\text { (4/3), Tokio Sato (5/3) }\end{array}$ & $\begin{array}{l}\text { Margarida Weisheimer } \\
(4 / 4)\end{array}$ \\
\hline 1951 a 1960 & $\begin{array}{l}\text { Carlos Eduardo Zimmermann (6/4), } \\
\text { Luiz Henrique Schwanke (7/5), } \\
\text { Marcos Jair Bento }(7 / 4) \text {, Richard } \\
\text { Bischof }(3 / 3)\end{array}$ & $\begin{array}{l}\text { Heloisa Maria Campos } \\
(4 / 3)\end{array}$ \\
\hline
\end{tabular}

Fonte: Paranaenses mais premiados nas 42 edições do Salão Paranaense (1986)

* (número de participação/número de premiação)

Desse grupo tem-se 40 homens e 7 mulheres, elencados por década de nascimento, no sentido quantitativo vê-se que: a participação das mulheres ainda é pequena se comparada a dos homens, e as primeiras participações femininas são as mulheres que nasceram entre 1911 a 1920. Destacando a produção das artistas mulheres que incidem nos anos 1970 e 1980, conforme quadro 2, três delas tem seu reconhecimento artístico no 
As mulheres artistas da geração 80 em Curitiba e as estratégias de permanência na posição de vanguarda no início dos anos 2000

decorrer da década de 1970 e início dos anos de 1980: Isabel Bakker, Margarida Weisheimer e Heloisa Maria Campos.

Isabel Bakker, nasceu em 1940 e faleceu em 1979, teve seis participações e quatro premiações na década de 1970, a primeira em 1972 com a obra "Violência" na linguagem de desenho, uma aquisição da Companhia Força e Luz do Paraná, e a última em 1976, também adquirida pela COPEL. Margarida Weisheimer nasceu em 1947, do total de quatro premiações: a primeira foi em 1971, a obra "Desenho I" adquirido pela Companhia Força e Luz do Paraná, e a última em 1978, as obras foram adquiridas pelo Banco do Brasil. Heloisa Maria Campos nasceu em 1953, teve três premiações no Salão: nos anos de 1979, 1980 e 1983. Essa última um prêmio em dinheiro pago pela Secretaria do Planejamento com a obra "Rótulos/Palavra/Texto", de 1983, uma instalação formada por duas garrafas de vidro com rótulos: Copo com Leite e Copo de Leite, dentro os objetos equivalentes.

Também com intuito de identificar as mulheres artistas atuantes no Paraná, seguimos com as colocações de Adalice Araújo (1980) que discorre sobre a década de 1970 nominada de Contemporaneidade, e, com isso, soma-se aos artistas destacados por Ferreira (1986) e Fontoura (1986). Araújo centra-se no grupo dos Encontros de Arte Moderna atrelado a EMBAP, faz menção a diferentes grupos como do Ateliê de Janete Fernandes e o de Suzana Lobo, apresenta os artistas com seus atelieres independentes. A produção artística abrange diferentes linguagens como desenho, pintura, escultura etc., entre as mulheres destaca os trabalhos de Alexandrina Rina Brami, Bia Wouk, Beatriz Corrêa, Beatriz Tosin, Carmen Carini, Celine Cury Palma, Daisy Aderne Carneiro, Margarida Weisheimer, Miriam Martins. Ligadas ao Grupo Ponto de Partida estavam Laila Tarran, Maria José Mendes, Ligia Beatriz Borba e Stela Schuchovski. No grupo de Janete tem-se a produção de Isabel Bakker, Maria Ivone Bergamini e Edilla Rezzi Feu. Entorno de Suzana Lobo agruparam Ruth Leite Ferreira e Cleuza Maranhão Salomão. 
Uma parcela das artistas mulheres destacadas por Araújo (1980), Ferreira (1986) e Fontoura (1986) tem sua representatividade validade pelo Salão Paranaense ao longo da década de 1980, tema apresentado a seguir.

\section{Mulheres na arte e seus vínculos com o Salão Paranaense durante a década de 1980}

Neste tópico objetiva-se mensurar o vínculo das mulheres no Salão Paranaense durante a década de 1980 e as diferentes posições ocupadas nesse certame artístico como artistas, júris, curadoras etc. Para tanto adota-se como fonte o catálogo "50 anos do Salão Paranaense de Belas Artes”, coordenado por Justino (1995) e que abrange as edições de 1944 a 1993, embora a prioridade nesse momento recai sobre as mostras realizadas entre 1980 a 1989. A respeito das participações das mulheres na categoria artista vê-se no quadro 3 a quantidade de artistas inscritos, aceitos e premiados, considerando a participação individual (homens e mulheres) e em grupo.

Quadro 3: QUANTIDADE DE ARTISTAS PREMIADOS NO SALÃO PARANAENSE (1980-1989)

\begin{tabular}{|l|l|l|l|l|l|l|l|l|l|l|l|}
\hline $\begin{array}{l}\text { Década } \\
1980\end{array}$ & 80 & 81 & 82 & $\mathbf{8 3}$ & $\mathbf{8 4}$ & $\mathbf{8 5}$ & 86 & 87 & 88 & 89 & Total \\
\hline Edição & 37 & 38 & 39 & $\mathbf{4 0}$ & $\mathbf{4 1}$ & $\mathbf{4 2}$ & 43 & 44 & 45 & 46 & \\
\hline $\begin{array}{l}\text { Artistas } \\
\text { Inscritos }\end{array}$ & 343 & 359 & 236 & $\mathbf{3 0 2}$ & $\mathbf{2 2 8}$ & $\mathbf{4 1 5}$ & 374 & 711 & 427 & 442 & 3.837 \\
\hline $\begin{array}{l}\text { Artistas } \\
\text { Aceitos }\end{array}$ & 124 & 124 & 99 & $\mathbf{1 8 0}$ & $\mathbf{6 8}$ & $\mathbf{1 3 2}$ & 155 & 216 & 102 & 80 & 1.280 \\
\hline $\begin{array}{l}\text { Prêmio/ } \\
\text { Homens }\end{array}$ & 20 & 24 & 14 & $\mathbf{8}$ & $\mathbf{5}$ & $\mathbf{7}$ & 10 & 11 & 5 & 4 & 108 \\
\hline $\begin{array}{l}\text { Prêmio/ } \\
\text { Mulheres }\end{array}$ & 12 & 9 & 7 & $\mathbf{2 1}$ & $\mathbf{6}$ & $\mathbf{8}$ & 5 & 3 & 2 & 1 & 74 \\
\hline $\begin{array}{l}\text { Prêmio/ } \\
\text { Grupos }\end{array}$ & - & - & - & - & - & $\mathbf{1}$ & - & 1 & - & - & 2 \\
\hline $\begin{array}{l}\text { Prêmio/ } \\
\text { Total }\end{array}$ & 32 & 33 & 21 & $\mathbf{2 9}$ & $\mathbf{1 1}$ & $\mathbf{1 6}$ & 15 & 15 & 7 & 5 & 184 \\
\hline
\end{tabular}

Fonte: 50 anos do Salão paranaense de Belas Artes (JUSTINO, 1995)

Nota-se que os anos de 1983, 1984 e 1985 houve maior número de mulheres do que de homens que obtiveram premiação, com destaque para o Salão realizado em 1983 que premiou 21 mulheres de diferentes Estados brasileiros. Atuantes no Paraná lista-se 13 artistas: Andréa Guimarães, Denise Roman, Eliane Prolik, Elizabeth Titton, Estela Sandrini, Guilmar Silva, Guita Soifer, Heloisa Campos, Janete Fernandes, Jussara Age,

Rev. Caminhos da Educação: diálogos, culturas e diversidades, Teresina, v. 2, n. 3, p. 48-71, set./dez. 2020 
As mulheres artistas da geração 80 em Curitiba e as estratégias de permanência na posição de vanguarda no início dos anos 2000

Letícia Faria, Lucia Steinbach e Uiara Bartira. Três do Rio de Janeiro: Ana Miguel, Cristina Salgado e Katie Van Scherpenberg. Três do Rio Grande do Sul: Carmen Barth, Carola e Isabel de Castro; e por fim, Cidinha Ferigoli de São Paulo e Dina Oliveira do Pará.

Dos 74 prêmios destinados as mulheres, dez delas tiveram entre duas ou três premiações. As atuantes no Paraná, destaca-se: Annette Skarbek (1984 e 1989), Denise Roman (1980 e 1983), Estela Sandrini (1983 e 1986), Heloisa Campos (1980 e 1983) e Letícia Faria (1983, 1984 e 1987). A premiação para outros Estados: Dina Oliveira (1981, 1983 e 1986), Lena Bergstein (1980 e 1982), Mariza Barros (1984 e 1986), Rosângela Ferreira (1980 e 1981), Solange Oliveira (1981, 1982 e 1985). Dentre os grupos, houve a premiação em 1985 para "Impressões digitais" formado por Denise Bandeira, Eliane Prolik e Laura Miranda. Ainda atuantes no Paraná elenca-se mais 12 mulheres com uma participação no Salão, na categoria individual conforme quadro 3, excetuando a mostra de 1983: Andréia Cristina Las (1985), Ângela Parra (1988), Beatriz Corrêa (1980), Claudia Rezende (1986), Eloisa Azevedo (1985), Everly Giller (1985), Laura Miranda (1984), Lirdi Jorge (1981), Lucíola Moreira Pinto (1981), Rosa Youko Kanematsu (1985), Rosana Guimarães (1987), Tania Vescovi (1985).

No Quadro 3 constata-se que o ano de 1984 foi o Salão que teve menor quantidade de artistas inscritos (228) e de artistas aceitos (68). Percebe-se também que o houve uma queda na quantidade de premiações comparando os anos de 1980 (32 premiações) e 1981 (33 premiações) com os de 1988 (7 premiações) e 1989 (5 premiações), respectivamente.

Quanto a participação das mulheres na posição de júris a proporção também é menor que a dos homens, seguindo o Quadro 4. Distribuídos em sete Estados brasileiros tem-se a participação de 34 júris, do total de 42 participantes, já que alguns membros participaram em mais de um certame, desses 5 júris são mulheres: Adalice Araújo (1980, 1983, 1985 e 1989), Denise Bandeira (1988) e Suzana Lobo (1988), do Paraná; Lisbeth Rebollo Gonçalves (1982) de São Paulo e Vera Chaves Barcelos (1981) do Rio Grande do Sul.

Rev. Caminhos da Educação: diálogos, culturas e diversidades, Teresina, v. 2, n. 3, p. 48-71, set./dez. 2020 

1989)

Quadro 4: QUANTIDADE DE JÚRIS NO SALÃO PARANAENSE (1980-

\begin{tabular}{|l|l|l|l|l|l|l|l|l|l|l|l|}
\hline Década 1980 & 80 & 81 & 82 & 83 & 84 & 85 & 86 & 87 & 88 & 89 & Total \\
\hline Edição & 37 & 38 & 39 & 40 & 41 & 42 & 43 & 44 & 45 & 46 & \\
\hline Paraná & 01 & 02 & 01 & 02 & 03 & 03 & 03 & 01 & 02 & 02 & 20 \\
\hline São Paulo & 01 & 01 & 01 & & & 01 & 01 & 01 & 01 & 01 & 08 \\
\hline Rio de Janeiro & 01 & 01 & 01 & 01 & 01 & 01 & 01 & & & 02 & 09 \\
\hline Santa Catarina & & & & & 01 & & & 01 & & & 02 \\
\hline $\begin{array}{l}\text { Rio Grande do } \\
\text { Sul }\end{array}$ & 01 & & & & & & & & & 01 \\
\hline Minas Gerais & 01 & & & & & & & & & & 01 \\
\hline Bahia & 01 & & & & & & & & & & 01 \\
\hline Total & 05 & 05 & 03 & 03 & 05 & 05 & 05 & 03 & 03 & 05 & 42 \\
\hline
\end{tabular}

Fonte: 50 anos do Salão paranaense de Belas Artes (JUSTINO, 1995)

Pelo quadro 4 dentre os júris homens atuantes do Paraná, 11 no total, a maioria representa a geração de artistas da década de 1960 e 1970: Aurélio Benitez (1981), Carlos E. Zimmermann (1983), Domício Pedroso (1989), Eduardo Rocha Virmond (1981, 1986), Elvo Benito Damo (1987), Ennio Marques Ferreira (1984, 1986), Fernando Calderari (1984), Fernando Velloso (1986), João Osório Brzezinski (1982, 1985), Ronald Simon (1985), Vicente Jair Mendes (1984).

Nesse sentido comprova-se a necessidade de o artista manter-se em cargos de peso simbólico no campo artístico ou mesmo exercer a docência como estratégia para complementar sua renda e conservar sua rede de sociabilidade, ações que para Sérgio Miceli (2002, p. 95-96) respondem as trajetórias sociais de artistas com "potencial" de consagração no campo artístico. Para preservar a posição de vanguarda os criadores enquadram-se em três grupos de artistas, os que: 1) tem ligações de parentesco com outros artistas; 2) provêm de famílias abastadas da elite econômica; 3) não conseguem sobreviver de seu trabalho artístico, complementando suas fontes de renda com empregos alternativos (professores, desenhistas, decoradores, etc.). Miceli (2002, p. 97) também discute a importância dos "criadores dos criadores" no mercado de bens simbólicos, visto que tanto a concepção de arte moderna quanto à concepção de arte contemporânea atinge um número restrito da sociedade, e que o acesso à obra por parte do público é intercedido pelas galerias e salões de arte, espaços que representam a figura do "distribuidor" segundo 
As mulheres artistas da geração 80 em Curitiba e as estratégias de permanência na posição de vanguarda no início dos anos 2000

Canclini (1986, p. 64), ou do "descobridor" como destaca Bourdieu (2002, p. 23). Portanto, a função dessas organizações no contexto atual é tão importante quanto a própria obra.

Essa validação é realizada pelos críticos de artes e júris de Salões, pelos marchands e pelos curadores - parte deles pelos seus vínculos sociais e políticos assumem o papel de intelectuais como alude Vieira (2006) - ao validarem simbolicamente a produção de um determinado grupo de artistas. Ao se referir a geração de 1870, Vieira elucida que a origem social dos intelectuais tinha como axioma:

\begin{abstract}
distribuição desigual da riqueza equivale, em regra geral, a distribuição desigual da cultura e do conhecimento. O problema de gênero também tem uma premissa bastante conhecida e compartilhada, uma vez que, segundo as representações prevalentes na época, cabia aos homens a ocupação do espaço público, enquanto que, à mulher, estava reservado o espaço privado, das tarefas domésticas e da vida familiar. Existem muitas exceções a essas lógicas estruturais e culturais, contudo elas apenas confirmam a regra. (VIEIRA, 2015, p.6).
\end{abstract}

Essas exceções também se aplicam as mulheres artistas, já que é menor a quantidade de mulheres premiadas no Salão Paranaense, no quadro 2 vê-se que foram consagradas apenas sete mulheres nascidas entre 1911 a 1960, do total de 47 artistas premiados.

Somente a partir de meados da década de 1980 as mulheres tem maior participação nesse certame artístico, de um lado, o aumento da visibilidade das mulheres nos espaços públicos decorre do processo acelerado de urbanização que se efetiva ao longo dos anos 1970, de outro, a partir da década de 1960 as pautas feministas no país se alinham ao feminismo de "Segunda Onda" como alude Joana Maria Pedro (2013). Nas palavras da autora: "direitos ligados ao corpo e à sexualidade, liberdade de expressão, participação no mercado de trabalho e educação igualitárias não eram as únicas bandeiras do feminismo de 'Segunda Onda'. O trabalho doméstico como um encargo feminino também passou a ser questionado" (PEDRO, 2013, p.250-251). Sendo que no Brasil as pautas do feminismo eram centradas nas lutas gerais ligadas as mazelas políticas e sociais,

Rev. Caminhos da Educação: diálogos, culturas e diversidades, Teresina, v. 2, n. 3, p. 48-71, set./dez. 2020 
debatia-se o fim da ditadura e as lutas em prol de uma sociedade mais justa e igualitária etc.

Particularizando a representação das mulheres no Salão Paranaense, nota-se que o termo curadoria aparece designando uma das funções que faziam parte dos membros da comissão organizadora a partir de 1986. Cumprindo esse papel de validação dos criadores, dentre as mulheres: em 1986, Tania Zaruch realiza a curadoria das mostras paralelas; Adalice Araújo e Nilson Burda realizam a mostra de 1987; Nilza Procopiak atua nos anos de 1988, 1989 e 1990; Karin Bachstein e Edson Macedo são responsáveis pelo Salão de 1992, sendo que a curadoria da Sala especial com a mostra "Exposição Latino-Americana de Artes Visuais/92" ficou aos cuidados de Macedo; e em 1993, a responsabilidade também é de Karin Bachstein. (JUSTINO, 1995).

Já mensurado as mulheres da posição de artistas, júris e curadoras, complementase sua representatividade no Salão Paranaense ao identificar quais delas tiveram obras expostas nas "Salas especiais", para tanto analisa-se os Salões realizados entre 1970 a 1989. No quadro 5 considerando os 20 salões realizados no período, 14 deles promoveram as Salas especiais. Nas Salas especiais apenas Yolanda Mohalyi (1909-1978) iv foi homenageada, excetuando o possível vínculo das mulheres nas exposições coletivas. Yolanda residia em São Paulo sua primeira exposição individual ocorreu em 1945, no Instituto de Arquitetos do Brasil - IAB/SP, sendo que em 1958 recebe o prêmio Leirner de Arte Contemporânea, dentre suas produções destaca-se as com temáticas sociais e as que retratam mulheres: "Desemprego" de 1931, "Jovem mãe” de 1943, "Mulata" de 1945 e a "Velha", sem data.

Quadro 5: PARTICIPAÇÃO EM SALAS ESPECIAIS - SALÃO PARANAENSE (1970-1989)

\begin{tabular}{|l|l|l|l|}
\hline Ano & Exposições / Artistas & Ano & Exposições / Artistas \\
\hline 1970 & $\begin{array}{l}\text { - Waldemar Curt Freÿesleben } \\
\text { - João Groff }\end{array}$ & 1980 & Rubens Gerchman \\
\hline 1971 & Guido Viaro & 1981 & $\begin{array}{l}\text { - Representação Brasileira na } \\
\text { V Exposição Internacional de } \\
\text { pequena escultura/Budapeste } \\
81 \\
\text { - Bené Fonteles }\end{array}$ \\
\hline 1972 & & 1982 & \\
\hline 1973 & Theodoro de Bona & 1983 & Theodoro de Bona \\
\hline
\end{tabular}

Rev. Caminhos da Educação: diálogos, culturas e diversidades, Teresina, v. 2, n. 3, p. 48-71, set./dez. 2020 
As mulheres artistas da geração 80 em Curitiba e as estratégias de permanência na posição de vanguarda no início dos anos 2000

\begin{tabular}{|l|l|c|l|}
\hline 1974 & $\begin{array}{l}\text { Rodolfo Amoedo: pintura e } \\
\text { desenho }\end{array}$ & 1984 & \\
\hline 1975 & Lange de Morretes & 1985 & $\begin{array}{l}\text { Centenário de nascimento de } \\
\text { Herman Schiefelbein: pinturas }\end{array}$ \\
\hline 1976 & Orlando Mattos & 1986 & $\begin{array}{l}\text { Retrospectiva Mário } \\
\text { Rubisnki: obra gráfica e } \\
\text { pictórica } \\
- \text { Artistas paranaenses mais } \\
\text { premiados nas 42 edições do } \\
\text { Salão paranaense }\end{array}$ \\
\hline 1977 & $\begin{array}{l}\text { Yolanda Mohalyi } \\
1978\end{array}$ & 1987 & $\begin{array}{l}30 \text { anos da revolução } \\
\text { modernista no Paraná }\end{array}$ \\
\hline 1979 & $\begin{array}{l}\text { - Arte de Mato Grosso, } \\
\text { - A escultura no Rio Grande } \\
\text { do Sul, } \\
\text { - Antonio Arney }\end{array}$ & 1988 & \\
\hline
\end{tabular}

Fonte: 50 anos do Salão paranaense de Belas Artes (JUSTINO, 1995)

Ainda pelo quadro 5, Theodoro de Bona (1904-1990) foi homenageado em dois momentos distintos: 1973 e 1983, e percebe-se que existe uma preocupação dos agentes locais em demarcar o momento da inserção da arte moderna no Paraná, tendo como marco o ano de 1957, pela mostra "30 anos da revolução modernista no Paraná". Tema revisitado por Freitas (2003), segundo o autor o alinhamento com as tendências artísticas do eixo Rio de Janeiro e São Paulo, como o abstracionismo, se oficializa em Curitiba por meio do Salão Paranaense no início da década de 1960.

Como parte do processo de consolidação do moderno na história da arte no Paraná, no final da década de 1950 e ao longo de 1960, Freitas (2003) destaca a revista de literatura e arte "Joaquim" em circulação entre 1946 e 1948, e a atuação dos artistasprofessores Poty Lazzarotto e Guido Viaro. Também menciona os espaços modernistas como a "Garaginha", nome dado ao ateliê da artista Violeta Franco, o Centro de Gravura e a Galeria Cocaco; e por fim, destaca os vínculos institucionais de Ennio M. Ferreira 
com o Estado. Dentre as mulheres que produzem a não-figuração no Salão Paranaense de 1961, 1962 e 1963 tem-se: Helena Wong e Tomie Ohtake, artistas mulheres que dividem a cena com João Osório Brzezinski, Antonio Arney, Fernando Calderari, Fernando Velloso, Jorge Sade, Waldemar Roza, Ianelli e Tikashi Fukushima (FREITAS, 2003).

\section{Considerações finais}

Sobre a efetivação das estruturas artísticas e culturais em Curitiba, salienta-se que a realização do Salão Paranaense no espaço físico do MAC/PR inicia-se com a mostra realizada em 1984, anteriormente Curitiba dispunha do "Salão de exposições da Fundação Teatro Guaíra" e da "Biblioteca Pública do Paraná" (Justino, 1995; Biora, 2019). O que elucida que o sistema de artes em Curitiba e suas estruturas institucionais começam a se organizar a partir de meados da década de 1970, e efetivamente no início dos anos de 1980, pela ampliação da oferta de ensino superior em Artes e pela sistematização de um mercado de arte comercial e simbólico como destaca Ferreira (1986), Fontoura (1986), Santini (2015), Autor 1 (2004; 2011), Autor 2 e Autor 1 (2020).

Constata-se que a representação das mulheres é menor que dos homens nas premiações do Salão, e demais funções simbólicas que representa esse certame. As mulheres que preservam suas posições de vanguarda no início dos anos 2000 atuaram na docência, assumiram postos de gestão e exerceram a função de curadoras etc.; isto é, integrando uma rede de sociabilidades entre os agentes sociais com envergadura política e cultural, que expande-se na década de 1980 e tem seu marco de atuação no início de 1960 (Freitas, 2003; Autor 1, 2004).

Uma parcela dessas mulheres que ingressaram no campo da arte em 1980, amplia suas ações do ofício como artistas e cumprem o papel de intermediárias culturais, posição essencial para sua manutenção no campo artístico como alude Bourdieu (1996, p.149) quando discorre sobre o "projeto criador". Dentre as mulheres com representatividade simbólica na década de 1980 mensurada pelo vínculo com o Salão Paranaense destaca-se a atuação das artistas Annette Skarbek, Denise Roman, Estela Sandrini, Heloisa Campos e Letícia Faria, mulheres com maior número de premiações entre 1980 a 1981, o que se conecta com a atuação de Adalice Araújo na posição de júri deste certame.

Nesse artigo não foi realizada uma abordagem interseccionalv, embora aconselhese a continuidade desse mapeamento mensurando a participação das mulheres negras no campo da arte no Paraná. Por outro lado, o presente estudo possibilita a visibilidade da

Rev. Caminhos da Educação: diálogos, culturas e diversidades, Teresina, v. 2, n. 3, p. 48-71, set./dez. 2020 
As mulheres artistas da geração 80 em Curitiba e as estratégias de permanência na posição de vanguarda no início dos anos 2000

produção feminina local ao elencar as mulheres atuantes no Paraná a partir da década de 1980.

\section{Referências:}

ARAÚJO, Adalice. Arte no Paraná I. Referência em Planejamento. Curitiba, v. 3, n. 12 , jan./mar.1980.

BIORA, Ellen C. P. O conceito de museu vivo na perspectiva da educação: o caso do Museu de Arte Contemporânea do Paraná (1970-1984). 167 f. Dissertação. (Mestrado em Educação) - Universidade Federal do Paraná, Curitiba, 2019.

BOURDIEU, Pierre. As regras da arte: gênese e estrutura do campo literário. São Paulo: Companhia das Letras, 1996.

BOURDIEU, Pierre. A economia das trocas simbólicas. 5. ed. São Paulo: Perspectiva, 2001.

BOURDIEU, Pierre. A produção da crença. 1. ed. São Paulo: Zouk, 2002.

CANCLIN, Néstor García. A socialização da arte: teoria e prática na América Latina. 2. ed. São Paulo: Cultrix, 1986.

CRENSHAW, Kimberlé W. Demarginalizing the intersection of race and sex: a black feminist critique of discrimination doctrine, feminist theory and antiracist politics. University of Chicago Legal Forum, 1989, p. 139-167.

FERREIRA, Ennio Marques. Das estruturas aos artistas. In: GOVERNO DO PARANÁ.

JUSTINO, Maria José (org.) Tradição e Contradição. Catálogo de exposição. Curitiba, 1986, p.121-137.

FONTOURA, Ivens. Explosão criativa durante os anos setenta. In: GOVERNO DO PARANÁ. JUSTINO, Maria José (org.) Tradição e Contradição. Catálogo de exposição. Curitiba, 1986, p.138-141.

FREITAS, Arthur P. A consolidação do moderno na história da arte do Paraná. Revista de História Regional. Ponta Grossa, n. 8, v. 2, Inverno 2003, p.87-124. 
FREITAS, Arthur P. O dilema da vanguarda: arte comportamental nos Encontros de Arte Moderna. In: XXVII Simpósio Nacional de História, 2013, Natal, RN. Anais do XXVII Simpósio Nacional de História, 2013.

FUNDAÇÃO CULTURAL DE CURITIBA. BERBEKA, A. et al. Acervo Contemporâneo Curitiba. Catálogo de exposição. Curitiba, 2000/2001.

HIRATA, Helena. Gênero, classe e raça: Interseccionalidade e consubstancialidade das relações sociais. In: Tempo social, revista de sociologia da USP, v. 26, n.1, jun. 2014, p.61-73.

JUSTINO, Maria José. 50 anos do Salão Paranaense de Belas Artes. Curitiba: Fundação da Universidade Federal do Paraná (FUNPAR), 1995.

MICELI, Sérgio. Mercado de Arte/Brasil 2000. In: MARQUES, R.; VILELA, L. H. (org.). Valores: arte, mercado, política. Belo Horizonte: Editora UFMG, 2002, p.79-106.

MOHALYI, Yolanda Lederer. In: MOHALYI, Yolanda Lederer. Enciclopédia Itaú Cultural de Arte e Cultura Brasileiras. São Paulo: Itaú Cultural, 2019. Disponível em: $<$ http://enciclopedia.itaucultural.org.br/pessoa8469/yolanda-mohalyi $>$. Acesso em: 23 nov. 2019.

PEDRO, Joana Maria. O feminismo de "segunda onda": corpo, prazer e trabalho. In: PINSKY, Carla B.; PEDRO, Joana M. Nova história das mulheres no Brasil. 1. Ed. 1. Reimpressão. São Paulo: Contexto, 2013, p.238-259.

SANTINI, Jacyara Batista. A educação artística no ensino superior: formação do professor em Curitiba face à LDB 5692/71. In: VIII Congresso Brasileiro de História da Educação: Matrizes interpretativas e internalização. Universidade Estadual de Maringá. Maringá de 29 de jun. a 2 jul. 2015, s.p.

SECRETARIA DE ESTADO DA CULTURA. BINI, Fernando. A. F., et al. Faxinal das Artes. Catálogo de exposição. Curitiba, 2002.

SECRETARIA DE ESTADO DA CULTURA. FERREIRA, E. M. Síntese do Paraná Arte Atual. Catálogo de exposição. Curitiba, 2002.

SECRETARIA DE ESTADO DA CULTURA. NORONHA, Maria Cecília Araújo. Paranaenses mais premiados nas quarenta e duas edições do Salão Paranaense. Catálogo de exposição. Curitiba, 1986.

COSTA, Marcus de Lontra e MATTOS, Armando. Anos 80: O palco da diversidade. Catálogo de exposição. São Paulo, Sesi; Rio Janeiro, Museu de Arte Moderna, 1995

Autor 2, 2002. (Retirado)

Autor 2; Autor 1, 2020 (Retirado)

Autor 1, 2011. (Retirado)

Rev. Caminhos da Educação: diálogos, culturas e diversidades, Teresina, v. 2, n. 3, p. 48-71, set./dez. 2020 
As mulheres artistas da geração 80 em Curitiba e as estratégias de permanência na posição de vanguarda no início dos anos 2000

Autor 1, 2004. (Retirado)

Autor 1, 2019. (Retirado)

VIEIRA, Carlos Eduardo. História dos intelectuais: representações, conceitos e teorias. In: CONGRESSO BRASILEIRO DE HISTÓRIA DA EDUCAÇÃO, 4., 2006, Goiânia, p. 1-11.

Disponível

em:

$<$ http://www.sbhe.org.br/novo/congressos/cbhe4/coordenadas/eixo06/Coordenada $\% 20 p$ or\%20Carlos\%20Eduardo\%20Vieira/Carlos\%20Eduardo\%20Vieira\%20-

\%20Texto2.pdf.> Acesso em: 11 mar. 2020.

VIEIRA, Carlos Eduardo. Intelectuais e Educação. In: Pensar a Educação em Revista, Curitiba/Belo Horizonte, v. 1, n. 1, p. 3-21, abr./jun. 2015.

RECEBIDO: 01/06/2020

APROVADO:03/08/ 2020
RECEIVED: $01 / 06 / 2020$

APPROVED: 03/08/ 2020
RECIBIDO: 03/08/ 2020

APROBADO: 03/08/ 2020

\footnotetext{
' A denominação Geração 80 é utilizada na História da Arte Brasileira para designar os artistas atuantes na década de 1980, que se alinhavam com o contexto social do fim da ditadura civil-militar e a abertura democrática. "havia a necessidade de uma produção artística que buscasse as ruas [...]. A nova geração queria fazer da arte o seu retrato e do Brasil [...]. Essa produção jovem, plural em suas manifestações, acabou por se traduzir no rótulo abrangente de 'Geração 80"' (COSTA e MATTOS, 1995, p. 12). Essa geração que não se limitava apenas ao eixo consolidado do circuito artístico Rio-São Paulo "ocupou as manchetes da mídia, os espaços de exposições coletivas, salões de arte e de bienais". (COSTA e MATTOS, 1995, p. 12).

ii Sobre o Curso de Artes Plásticas na Educação (CAPE) consultar as pesquisas de Autor 2 (2002) e as interlocuções com o ideário da Escolinha de arte do Brasil apresentado por Jacyara B. Santini (2015).

iii Para detalhes sobre os vínculos com a Universidade Federal do Paraná, Autor 2 e Autor 1 (2020) abordam sobre os cursos de graduação vinculados ao Departamento de Artes dessa instituição, os quais se estruturam em meados da década de 1980.

iv Pintora, desenhista. Na Hungria estuda pintura na Escola Livre de Nagygania e, em 1927, ingressa na Real Academia de Belas Artes de Budapeste. Em 1931, vem para o Brasil e fixa-se em São Paulo, onde leciona desenho e pintura. YOLANDA MOHALYI. In: ENCICLOPÉDIA Itaú Cultural de Arte e Cultura Brasileiras. São Paulo: Itaú Cultural, 2019. Disponível em: $<$ http://enciclopedia.itaucultural.org.br/pessoa8469/yolanda-mohalyi $>$. Acesso em: 23 nov.2019.
}

Rev. Caminhos da Educação: diálogos, culturas e diversidades, Teresina, v. 2, n. 3, p. 48-71, set./dez. 2020 
${ }^{v} \mathrm{O}$ termo interseccionalidade designa a interdependência das relações de poder de raça, sexo e classe apresentado pela primeira vez por Kimberlé W. Crenshaw em 1989 - como alude Helena Irata (2014).

Rev. Caminhos da Educação: diálogos, culturas e diversidades, Teresina, v. 2, n. 3, p. 48-71, set./dez. 2020 